\title{
Interaction of analogic and digital workflows for architectural design and production
}

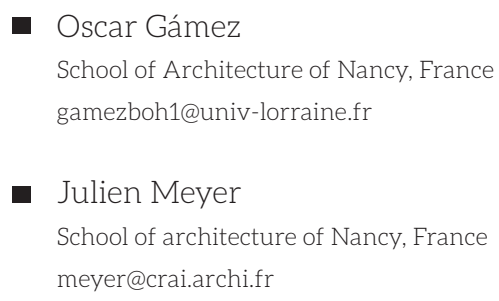

\author{
- Jean Claude-Bignon \\ Map CRAI, France \\ bignon@crai.archi.fr \\ - Gilles Duchanois \\ Map CRAI, France \\ duchanois@crai.archi.fr
}

\begin{abstract}
Architectural conception often faces challenges regarding the way a design becomesreal. Today's digital tools make possible toconceive and produce more defying architectural objects, which needs special abilities in the field of modeling and programming applied to design. The work presented in this writing, shows how actual digital methods of conception and production are underpinned on traditional procedures of conception and construction as it looks back on the way traditional techniques come to help the digital approach, when the latter is not achieved the way and by the means it is intended to.
\end{abstract}

Keywords: Digital Conception, Robotic Fabrication, Non-standard Architecture, Wood Construction

\section{Introduction}

Digital conception the way we know it today has been evolving rapidly during the last 15 years, we only need to take a look at the postulates made by Lynn (Lynn, 1999) and the references he used to cite at that time. Since then, materializing non-standard complex structures has become easier in terms of cost and time, all because technology is (maybe) quite more affordable, modeling software and computers became more powerful and robotics is no longer exclusively used for serial production purposes. A concept that is particularly true if we look at the contemporary trend of making ephemeral structures, which have in common the fact of being conceived with specialized software and produced using CNC machines and/or robots. The cases are numerous, from experimental and elaborated prototypes like the Endless Wall (Kondziela, 2011) to more commercial productions such as the Kreod Pavilion (Li, 2013), the resource seems always to be the same: A parametric modeling framework followed by the automated or robotically assisted production of the conceived architectural form.

Regarding these matters, herein we present a study that explores four cases of conception and production of prototype-like architectural forms which not only use digital modeling and robotics as means to achieve a result but call for traditional techniques to conceive, build and/or finish wood- made architectural objects whose morphological features can be considered as non-standard.

By the end of this paper, it will be shown how student teams and researchers face the constraints and challenges from each approach and get the better from a given material which can be Cross laminated Timber (CLT), Laminated Veneer Lumber (LVL), Plywood, Glued Laminated Timber (Glulam), Medium Density Fiberboard panels (MDF) and/ or Oriented Strand Board panels (OSB). A discussion dealing with the complementarity between these approaches will explain why a certain degree of craftsmanship cannot be dissociated (yet) from contemporary assisted conception and automated construction.

\section{Study Background}

The School of Architecture of Nancy- France (ENSAN) and the Center for research in Architecture and Engineering (CRAI) lead a project called Ecofab whose purpose is to develop non-standard wooden structures underpinned on the concepts of parametric modeling, material rationalization and assisted production (by automated means). The experimentation environment of the project is supported by a yearly academic workshop named "Conception and Digital Fabrication (CDF)" which is conducted with the participation of the students of the ENSAN. In this workshop students explore the design spectrum of parametric modeling and as 
result, they get to produce non-standard structure models fabricated with a laser CNC machine.

The study scope covers another academic workshop known as the défis du bois (wood challenges) which deals with the making of real size architectural-structural objects. It takes place every year at the town of Épinal - France, and is led by the National School of Technologies and Wood Industries (ENSTIB) and the ENSAN. It dealt, until 2014, with the conception and construction of innovative wooden structures by using traditional methods.

These two scenarios combine the elements studied herein and reveal the complementarity between two environments: a) the digital, represented by digital modeling and automated fabrication and b) the traditional, represented by standard drawings and the use of human controlled tools in construction stages (Sharif, 2015).

\section{Case Study: Aim and Conceptual Approach}

Thestudy presented in this paper aims to show how digital methods of conception and production are underpinned on traditional procedures of conception and construction; it also analyzes the way traditional methods come to help the digital approach when it is not achieved by the means it is intended to. As result, the study is divided into two axes analyzing two cases each:

\section{Axis 1. Experimental research}

It concerns the work performed by students in the fields of parametric modeling and digital fabrication (digital approach) as well as in traditional conception and construction (traditional approach). Two cases, on different frameworks, are studied: The first one, referred before as the CDF workshop, deals with scale non-standard architectural prototypes conceived through parametric modeling (by using Rhinoceros and Grasshopper) which are then materialized through CNC laser cutting. The second one, referred as the wood challenges, tests the ability of several student teams to conceive and build real size innovative structures each, using a standard conception approach (hand-drawings, sketches, basic calculations) and conventional construction techniques in which digital modeling and automated machines are rarely used.

The CDF conceptual approach is referred to forms in nature that can be emulated and turned into architectural shapes: waves, trees, rocks, sand dunes; so they can be abstractly transformed. Then, students must extract an architectural object out of those shapes and create a non-standard structure based on it, using the modeling environment offered by Grasshopper. In order to make the exercise closer to reality, students must assume, the panels they use, represent real size CLT ones with specific physical properties. At such point, they are pushed to think about structural stability and building details as they are also concerned by the way those panels will be machined, transported and mounted under real conditions. In other words, they must understand that parametric modeling is not representative but constructive and requires full anticipation of construction stages.

For the Wood Challenges, teams must propose various alternatives that are material dependent, meaning that each team is given a specific material to work with, having to adapt their design to specific constraints so every design becomes singular because of the formal and structural approaches regarding the physical condition of material (CLT, LVL, timber...). On the other hand, since the room for digital modeling or structural simulation is limited, students are required to make scale models to figure out the project's aesthetics, the way elements will fit together, how they will be cut up and mounted.

\section{Axis 2. Applied research}

It is represented by two research cases in the field of computer-aided architectural design and digital fabrication, developed in a research laboratory, as part of the "Eco-FAB" project that focuses on plywood, CLT, and LVL structures conceived through principles of folding and cellular pattern subdivision of non-standard architectural forms.

The first case, presents the concept of folding as a method to achieve structural stability and aesthetic quality, a feature that few designing and construction methods can achieve. This is particularly clear considering that folded structures use thin panels to cover long spans acting as supporting elements as well as finished envelopes, at least in the case of LVL and CLT panels (Stavric, Wiltsche, \& Bogensperger, 2015). Such concepts are validated with the construction of a full scale prototype for which comprehensive parametric modeling was necessary in order to anticipate the whole of its construction and fabrication constraints.

The second case, explores the usefulness of cellular subdivision applied to non-standard façade walls and envelopes. A concept underpinned on the principles of digital morphogenesis in architecture, defined by S. Roudavski (2009) as "a group of methods that employ digital media not as a representational tool but as generative tools for the derivation of form and its transformation... often in an inspiration to express contextual processes in built form...", which uses geometric patterns as a "mechanism to explore cells as structural components created by parametric modeling" (Gámez, Bignon, \& Duchanois, 2015). The aim of this approach is to enrich the constructive dimension and design possibilities of cellular wooden-structures applied not only to ephemeral constructions but to permanent architectural objects, as a design alternative in which patterns play an aesthetic and structural role by transforming the components of a wall into cells that can be easily assembled and mounted in an endeavor to optimize material consumption and execution time. A full scale plywood prototype in which assisted and traditional manufacturing techniques were merged in order to achieve a parametric-conceived architectural shape, served to validate the approach. 


\section{How deep goes traditional woodworking into a digital} conception-to-production workflow?

Standard workmanship still makes part of building activities even when contemporary tools aim to automate (or accelerate) all the phases from conception to construction. Nevertheless not everything can be done with a computer along with a CNC machine or robot, there is still a lot of work to do by hand and here we talk about direct human intervention. It is a fact that actual software allows a lot of anticipation avoiding improvisation at the moment of making. An advantage contemporary designers have and, for them to take advantage out of them, a lot of knowledge on informatics is necessary (Scheurer, 2010) but, where is the feedback coming from material?

In ordinary practice, most architects and engineers have a feedback from the people who actually build or make what the first intend to do, they propose a material, discuss the whereabouts of making it and maybe it is done. Some others go beyond and learn to feel materials a bit close to the way a carpenter would (and we talk specifically about wood construction), but they do not get to have the same feeling that the person who handles the material has. As Gramazio states, "... today the action of material handling is indirect through the use of $\mathrm{CNC}$ machines as opposed to the instant feedback about the work in progress the skilled manufacturer received through the tool in hand" (Gramazio, Kohler, \& Oesterle, 2010).

In some cases the use of $\mathrm{CNC}$ machinery can result in a hard and time consuming endeavor which can lead to opt for hand-making, depending on the size of the elements to produce, as stated in the work of Stavric, Wiltsche and Bogensperger when they talk about the construction of a prototype in which "inclined miter-cuts were manufactured by hand, since the production of the small sized panels was too time-consuming for professional CNC machines" (Stavric et al., 2015). A similar case will be discussed further. Considering this framework, in the upcoming paragraphs we will show at which level the traditional approach participates from the digital conception-to-construction workflow (if it exists).

\section{Case Outcome}

\section{First Outcome: CDF workshop}

As mentioned before, during this workshop students must emulate forms in nature and transform them into architectural shapes thus into non-standard structures. The results emerge from a parametric modeling exercise in which students prove to have knowledge enough to turn these forms into algorithmic operations as required by the grasshopper environment. The parametric approach is oriented towards 2D laser cutting (Figure 1).

The resulting digital model should meet the following requirements to achieve its production through $\mathrm{CNC}$ laser cutting: a) Structure stability. As the model represents a real size structure, it should prove to be stable even if it is not structurally analyzed; an empirical evaluation assesses the theoretical stability of the structure (moments, effort vectors, and slimness). b) Joinery. Joints must be parametrically defined in order to make the design adjustable at all moments; since joints make part of the carpenter's traditional knowhow, they must be digitally re-introduced. c) Size of elements. Structural members should fit in a plywood or MDF sheet; their dimensioning should consider the possibility of being made in real size and its effects over a real mounting operation. d) Assembly method. Teams should figure out a method to put all the elements together, at least at the scale of the model. With this in mind, the final workflow is divided in six parts: a) conception-abstraction, b) parametric modeling, c) file exchange, d) laser cutting, e) cleaning and f) assembling. Nonetheless, a seventh stage consisting of making some joints (like miters) manually appeared for some teams. Intended or not, for some prototypes a $2 \mathrm{D}$ joining system did not satisfy the formal requirements of their structures so they were forced to finish the "machining" by hand.

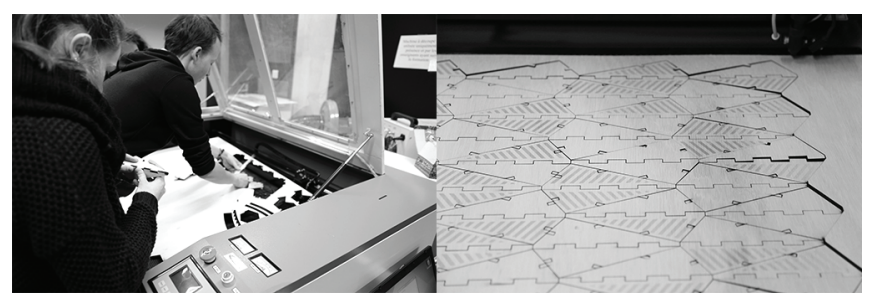

Figure 1: Fabricating models using a laser $\mathrm{CNC}$ machine.

\section{Second Outcome: The Wood Challenges}

The 2014 and 2015 editions of the wood challenges showed a different approach in the way that the last version totally introduced the use of digital modeling when conceiving the projects; a feature that enriches the discussion as the dimension of what is conceived and built is, in some manner, improved.

Before 2015, the wood challenges were an academic workshop in which students from engineering and an architecture schools were asked to design and build innovative structures starting from a basic concept: cantilevering, sheltering, overhanging [....] In some cases teams were able to choose the material to work with, in some others specific material was proposed to them. These aspects made the design experience challenging since students had to adapt a specific concept to a given material and vice versa (Figure 2).

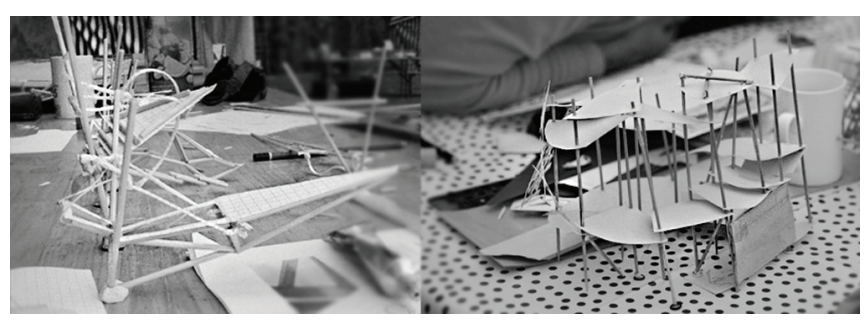

Figure 2: Matching form with concept and material. 
The conception stage is basically made following the traditional approach; however, the use of digital tools for structural evaluation was gradually introduced. Since the creation of the wood challenges the premise was to use the traditional approach through the entire workflow, though as structures became more audacious in terms of geometry and physical behavior, the notion of structural simulation by lines and nodes became essential since no risks could be taken.

Because of the outcome of this manifestation being open to the public and teams being working around the structures at all times, structures needed to prove structural reliability. For the rest of the conception tasks students must sketch and draw their structures, make scale models and nest structural items manually (Figure 3).

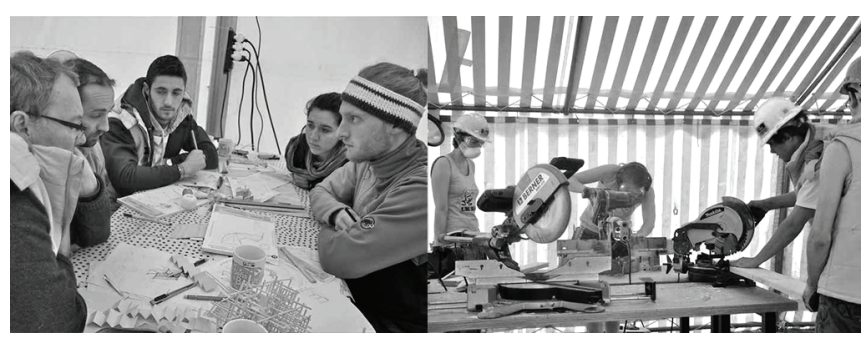

Figure 3: Traditional approach in conception and manufacturing.

On the execution plane, the exercise is even more demanding; teams must trace, verify, carve and cut timber pieces and panels with standard tools to fit items together (Figure 4). Students must mount the structures, for which purpose, the manner the structure will be made and which efforts affecting it whilst being raised must be fully anticipated; a task often made by carpenters which turns up to be managed by designers.

So far, activities follow the traditional approach with digital tools taking a slight participation in the conception stage so students need to adapt themselves to the means they have. There is a constant feedback from the structure (and material) but, since perhaps students do not have the full capacity to anticipate the entire operation to produce and raise the structures, or simply because there is no time enough to do so, they often face the fact of resolving detailing problems in-situ and find themselves confronted to discuss them on the go; the lack of experience plays an important role in this matter.

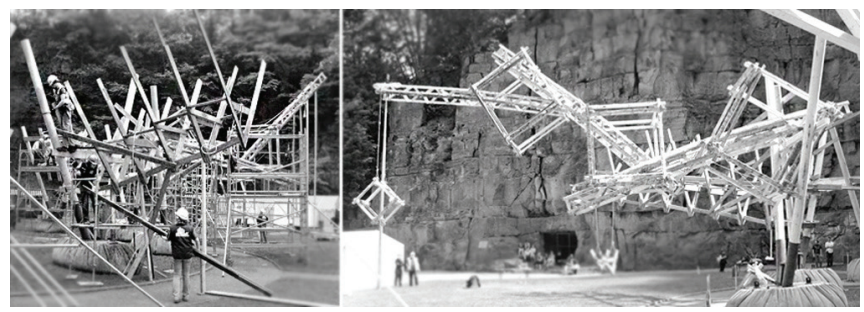

Figure 4: Cantilever structures. Mounting and final result.
The 2015 version of the wood challenges had the same approach in the execution phase but not for conception. This time, projects were conceived using digital tools (Rhinoceros, Sketch up, Archicad, Revit -among others-) which allowed having a deeper look into details and construction procedures (Figure 5). The final result is different from what it used to be in precedent years, structures are not ephemeral anymore and they are conceived to remain in time and place. The aim does not only focus on innovative structures but innovative huts for holidays; functional spaces that consider the minimal requirements for a place to be inhabited.
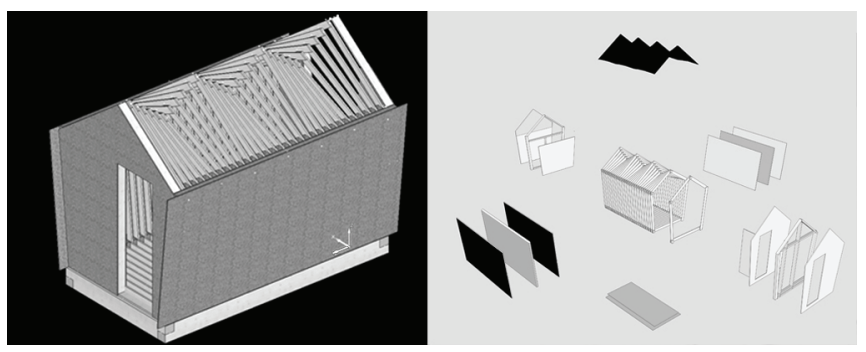

Figure 5: Digital modeling and building logistics sequence.

In terms of logistics this technique goes further regarding anticipation for execution, some tasks are still solved on the go and the interaction with materials is wider. At this point, one could think that $\mathrm{CNC}$ machining could give an important boost to the whole process with conception taking a little longer, which in the end would give more room for tuning up constructive details, improving the overall quality of the exercise.

\section{Third Outcome: a Folding Prototype}

The first project of the second axis of this study is a research project. Having the fold as morphological and structural principle, the aim of the prototype presented herein is to validate the usefulness of a computer-aided architectural design tool still under development.

It deals with the concept of Non-standard architecture as exploration of "the logic alternatives of repetition" (Oxman, 2006) possible through contemporary production techniques that allow for the customization of complex shaped components and items. The concept of variation is essential, as stated by B.Cache: "a series of objects which are similar but different nevertheless, just the same way a dune becomes a singular variation of the same morphological theme" (Cache, 1998).

In this context, free form emerges from a "digital morphogenesis" process, understood as generative tool for form derivation transformation (Kolarevic, 2005). Unlike the appearance emphasis of form-finding, digital morphogenesis focuses on material performance and processing instead of focusing on representation (Leach, 2009). Such digital process paves the way for generating an infinite variation of form creation. 
Concerning non-standard and free-form architectural shapes, folded-plate structures represent a creative building and structural solution through tridimensional combinations (Sekularac, Ivanovic-Sekularac, \& CikicTovarovic, 2012). The bond between an idea and the technical means to materialize it (architectural tectonics) leads to visual evidence that juxtaposes a constructive concept over a plastic form aimed to fit into a material and structural dimension (Frampton, 2001). By joining the universe of structural shells with that of architectural spaces, a continuous system of surfaces that integrates auto-stabilizing and auto-protecting functions is created.

The digital flow, to which we refer to, is described in "computer design and digital manufacturing of folded architectural structures composed of wood panels" (Meyer, Bignon, Duchanois, \& Bouali, 2015), and integrates a parametric modeling phase of morph-structural skins combined to a robotic fabrication process.

To validate the accuracy of the parameters used in the conception, stage as well as for the construction phase, a full-size prototyping experiment was proposed in order to see how modeling parameters for fold-plate structures are associated to criteria such as modeling (amplitude, frequency), material (rigidity, thickness), structural behavior (stability, stiffness) and fabrication (raw panel cutting up and weight management). In other words, the kinematics management of a mounting process allows for verifying the accuracy and feasibility of digital-joint parameters from the woodworking point of view.

To ensure a continuous data flow between conception and fabrication processes, the digital environment set for the prototyping experiment presented herein needed a threestep format exchange (Step - Btl - Iso) which meant an equal degree of data-continuity break and information loss when migrating from one format to another, a subject that becomes more complex when realizing the fact that making complex architectural shapes lies entirely on the tools used for such purpose. Said so, the dynamic flow of the morphological genesis conferred to such complex structures is, perhaps, not attached to the resulting form but to the technological means to achieve it. Despite of the available tools, numerous manual actions were necessary to accomplish the making of the folded prototype (Figure 6).

The first one was the splitting the LVL panels which were too big to be taken to where the robot was located. On a second stage, dovetail joints needed several manual operations to fix imperfections found after milling was finished; so did occur with some woodworking tasks that required manual carving since a few joints were not digitally programmed, therefore not executed by the robot. A third stage for finishing activities like sanding and removing after-milling debris, was necessary.

By the end, a mounting test of the whole prototype allowed for the verification and fixing of minor complications found after the milling phase. For the ongoing research projects covered by this axis, an inventory on these
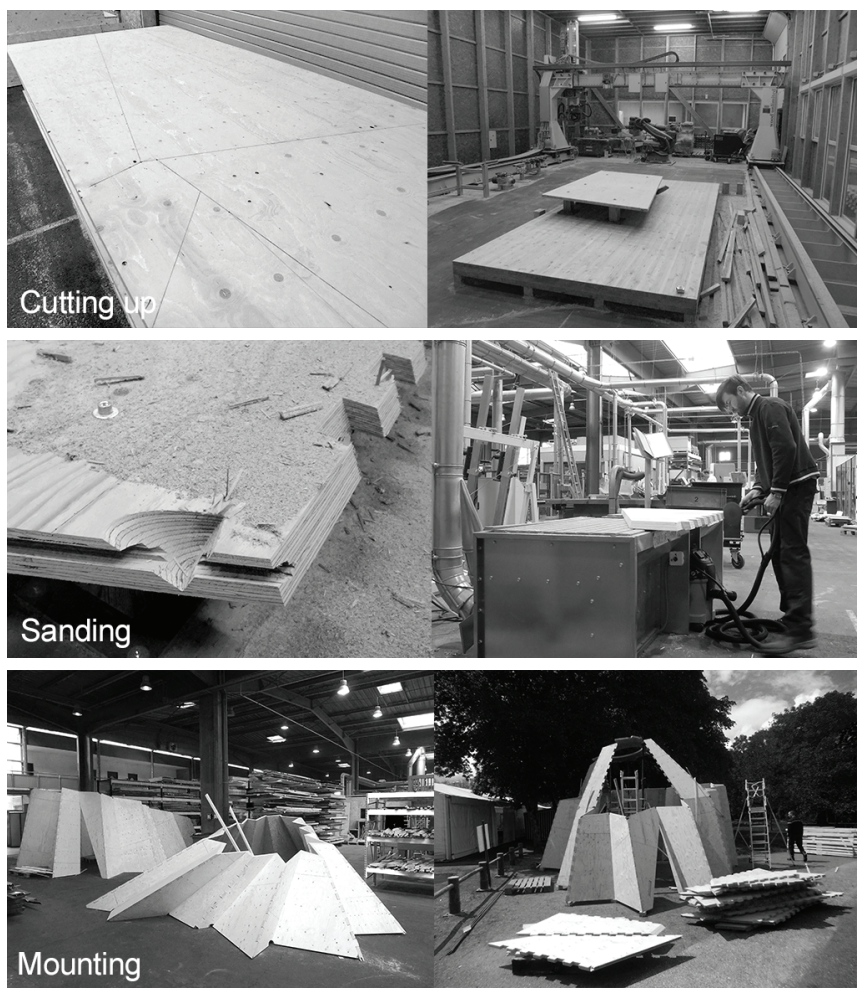

Figure 6: Manual actions needed to achieve the prototype

manual operations helps to better define and anticipate the needs linked to digital fabrication processes so machining parameters can be foreseen in conception phases and then integrated to parametric modeling methods.

The obtained results show that the tasks of conception and materialization of architectural objects, in contemporary praxis, need digital tools that emerged from the mixture between architecture and technology (Zellner, 1999). Such results come to prove that when conceiving free-form architectures, even by starting from physical models as shown in the work of F. Gehry, the use of digital tools remains fundamental. For such form-finding exercise, the traditional approach (modeling, sketching) emerges as complementary action of the digital conception workflow. Static representations such as sketches and models become relevant, for digital models to take form, since they fix an instant in form-finding without a solution of continuity (Figure 7).

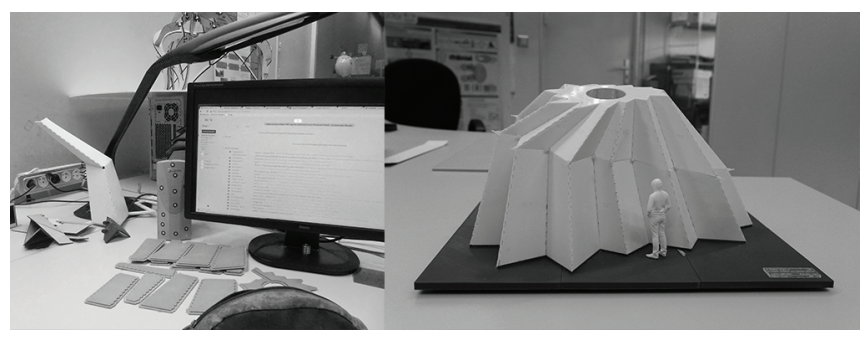

Figure 7: Static model made using 3D printing. 
Technical variables like structure, fabrication, mounting and materiality, act as merging elements of the genesis in architectural conception. Such variables (understood as a formalization process) represent a reconfiguration of the fold as a tool to obtain an acceptable folded shape instead of an optimal one; however, the digital continuum is not complete (by itself) and needs manual actions that can be found either in the digital conception phase or in the $\mathrm{CNC}$ machining stage. In a way, the use of the traditional approach allows for the development of the digital conception chain by providing elements that should be reproduced and improved digitally, which in the end, is essential to maintain an equilibrium regarding imaginative and constructive approaches as to avoid a breach between what is virtually possible and what is physically feasible.

\section{Fourth Outcome: Cellular-Patterned Wooden Walls}

The last subject of study is the product of a research project in the field of cellular patterns used as morphological approach for a conception to production workflow applied to non-standard wooden walls. Considering the principles of morphogenesis in architecture discussed by B.Kolarevic (2005) and S.Roudavski (2009), along with the usefulness of geometric patterns as basis for structural conception, the concept of cell as product of surface subdivision by means of a pattern, arises as to define the unit that will morphologically and structurally redefine a non-standard wall for use in facades and/or architectural envelopes (Gámez et al., 2015).

Following a model based on discreetness instead of the continuity of form (Carpo, 2015), this research project aims to develop a computer-aided architectural tool that will allow to define and/or redefine the inner structure of a non-standard wall to transform it into a cellular prefabricated structure (Figure 8). It deals with the benefits of prefabrication based on mass customization (Anzalone, Vidich, \& Draper, 2009) in a time in which mass-produced variations don't mean an extra cost (Carpo, 2005), something well explored in the wood construction industry by German and Swiss units like design2production or the Ibois.

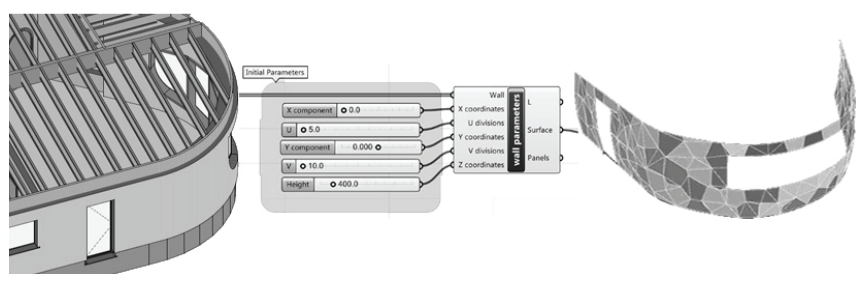

Figure 8: A given wall is structurally redefined by a pattern via parametric modeling (left image by Dform Architecture).
The early achievements on this matter are validated by building a full scale prototype involving two pattern morphologies (a grid and a Voronoi), an exercise that allowed to test a digital chain from parametric conception to mounting. For such purpose, the digital conception environment must integrate each phase of the process taking account of the following aspects: a) Machining environment. Robot/CNC machine tools and features; b) Joinery. Just as in the CDF workshop, the parametric model must "digitize" existing joining techniques to apply them to the architectural form structural components; c) Material. Thickness and Size are considered for nesting operations; d) Transport and mounting.

Produced items (once assembled) should have a size suitable to be handled by a person or two therefore its weight should match this criterion. For transportation purposes, as structural units are assembled in workshop, items should fit into a specific truck type.

As well as in the case of Origami Theatre (Stavric et al., 2015); here, the problem of dealing with small parts being treated with a huge machine was present too, thus the complexity lies in the quantity and shape of the objects to be processed. If we take a look at the intricacy each chosen pattern represents (Weaver, 1948; Gámez et al., 2015) the items coming from the Voronoi-patterned structure are more complex (in terms of shape) than those coming from the grid-patterned prototype.

The difference is simple but it highly increases CNC programming and cutting complexity. Whilst the grid-patterned structure items only have rabbet joints, the Voronoi-patterned structure contains rabbets and miters that have as many angles and intersections exist in the pattern. Programming and cutting those joints for being machined on $12 \mathrm{~mm}$ plywood was excessively time consuming and the machine was just too big to process more than a hundred manifold 400 x $300 \mathrm{~mm}$ size items. For that reason, most miters have to be made with standard machinery (shapers and saws) calling for the traditional approach to be used as a means to achieve a digitally conceived architectural form. As for the rest of the prototyping test, mounting is made manually; all of the structural components are pre-assembled in workshop and the mounting operation consists of putting one piece over another, fix them together, adjust levels, verify verticality and stability. These tasks are done by using power tools and it takes up to two people to mount each prototype (Figure 9). 

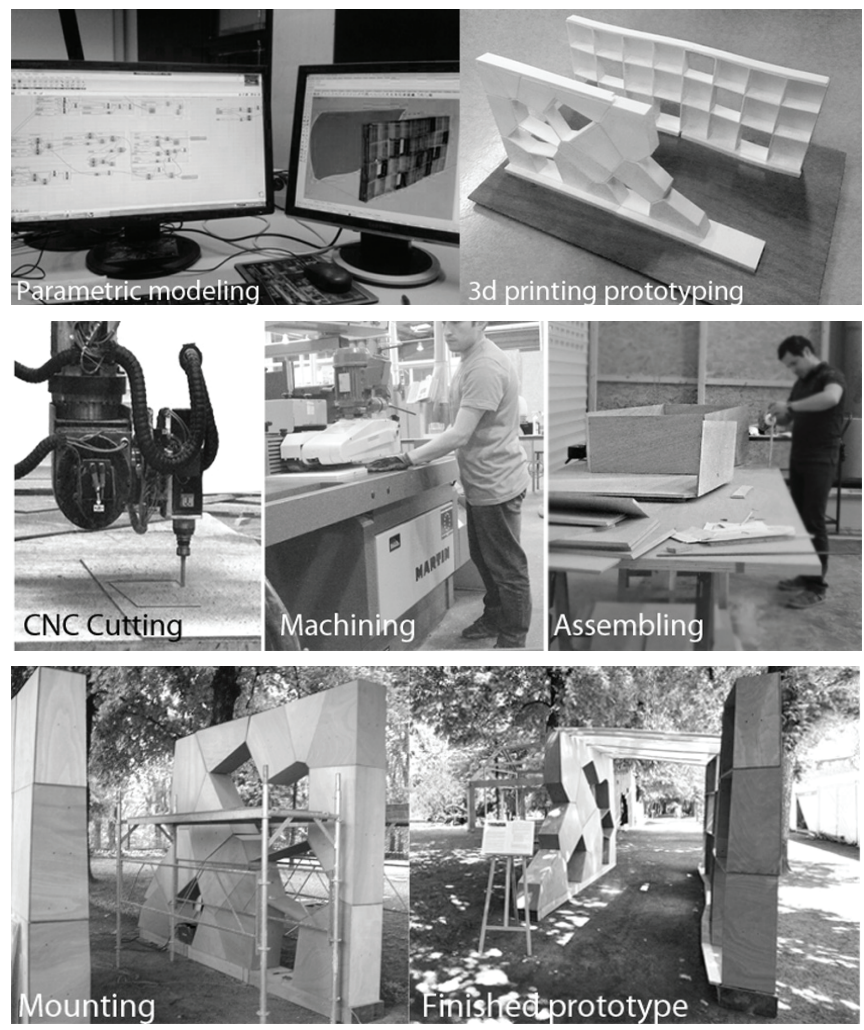

Figure 9: Patterned-prototype. Conception to production workflow.

\section{Outcome analysis}

To evaluate the usage of digital and traditional tools in the making of the projects described herein, we asked some of the workshops participants to fill out a survey analyzing the load taken by traditional and digital techniques of conception and production when carrying out a design-to-production workflow. The survey, presented the concepts under study as:

- Digital approach: The activities related to conception and production of architectural objects involving digital means. These digital tools can be computers, laser scanners, digital cameras, 3-D printers, CNC milling and laser machines (Among many others).

- Traditional approach: The actions in design and production requiring the participation of hand-made work, even when using a specific range of tools which are not digital and/or automated therefore needing the presence of a human to master them, these tools can be (but are not limited to): sanders, shapers, drills, routers, jigsaws, saws (all kind), hammers, screwdrivers, lifters, cutters.

The survey assessed the use of both approaches in activities such as sketching, modeling, nesting, milling, assembling, finishing and mounting. The average of the results is shown in Figure 10.

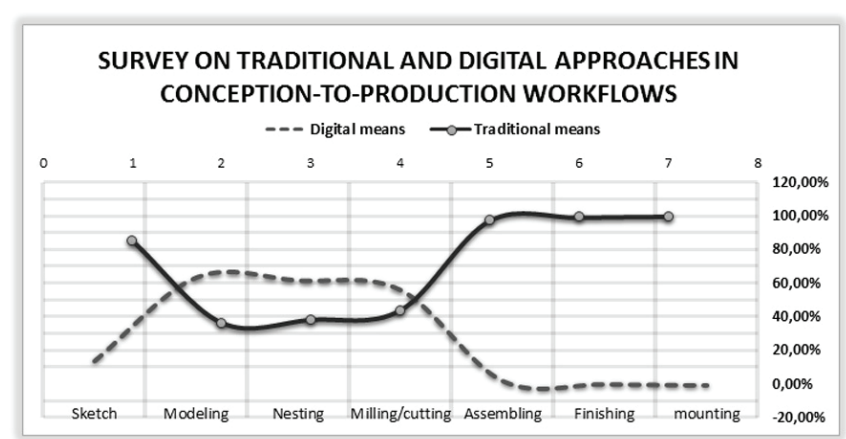

Figure 10: Survey results. Traditional approach strong in sketching and execution.

The graphic evidences that, in most cases, the chain begins with a traditional design process which turns into a digital procedure to generate plans and fabrication commands. The last stages are always made by hand since full automation is completely absent and human intervention is necessary for the logistics of mounting and assembling regardless of the scale of the architectural object produced.

\section{Discussion}

The cognitive process in architectural design calls for a model to precise the features of the designed object. Such model, from the architectural point of view, does not take the shape it would in engineering. The conceptual model in architecture considers the variations of form and function intrinsically in order to formulate visual alternatives to solve a specific problem in an abstract way. It is the principle of abstraction that keeps the world of design, at least in the sketching phase, on being an activity governed by the human brain which is transferred to the hand to be represented as drawings or physical models; in some manner, this is what Bignon describes as semantic and analogic models (Bignon, 2014). The way architectural design is made today, merges the concepts of what we have defined in this paper as traditional and digital approaches.

There is no objection that contemporary architectural practice requires the use of digital tools not only to accelerate the process itself but to achieve complex architectural shapes. On the other side lies the production chain. Whilst conception tasks (at almost all levels) mostly function in a digital environment; fabrication and production methods are not $100 \%$ used in automated mode. Depending on the scale of the object to produce, this last stage increases or not the use of digital and automated tools as is the case of 3D printing, in which producing an object is something that flows directly from the computer to the machine that materializes it.

In wood construction the used of automated machinery 
for producing standardized components is a common feature, so producing detailed components requires human intervention in most cases, which is the reason why it is not rare to see people manually performing woodworking tasks to finish specific assemblies in carpenter workshops and exploratory environments such as those described in this paper.

The cases exposed herein make prove of how traditional production methods driven by the action of human work have turned into digitally driven conception and production procedures(Sharif, 2015); however, thefact is that not everything has turned into digitally driven. For digital conception to be highly accurate in terms of digital fabrication, the designer must have a comprehensive understanding of material and building procedures in order to propose an architectural solution that will be concatenated into a digital model.

Most of times, architects and engineers get feedback only from what they see in their screen therefore they solve the problems they see more or less thoroughly. Yet, the details escaping the eye will become null or erroneous data that will later lead to fabrication or construction difficulties. It is worth to tell that, in order to achieve the necessary accuracy to compile constructive details into a digital model, the designer must get into the maker role and try to anticipate all the fabrication and construction phases into the digital model in order to make digital fabrication reliable. With no doubt some experience in the building of things will add a wiser approach towards an optimal digital model.

In some way, even if the data contained in a digital model is not entirely materialized by automated means, the information contained in it should give an outcome useful enough to create its contents by using the traditional approach (as seen in previous paragraphs). In the end, the symbiosis between the digital and the analogic approach form a feedback loop in which each other is complimentary and, perhaps for a short period in the history of architecture and wood construction industry, cannot be entirely dissociated.

\section{References}

Anzalone, P., Vidich, J., \& Draper, J. (2009, June 22). NonUniform Assemblage: Mass Customization in Digital Fabrication - Non-Uniform_Assemblage__Mass_ Customization_in_Digital_Fabrication.pdf. Retrieved October 20, 2014, from https://acadia.s3.amazonaws.com/paper/file/ PD26RH/Non-Uniform_Assemblage__Mass_Customization_ in_Digital_Fabrication.pdf

Bignon, J.-C. (2014). Les Défis du Bois. Une aventure architecturale, humaine, environnementale, technique et poétique. Épinal, France: Ministère de la culture et de la Communication, France Bois Forêt, Labex ARBRE, Fédération Française du Bâtiment, Union des métiers du Bois.

Cache, B. (1998, November 1). Vers un mode de production non-standard. Subjectiles et objectiles. Les cahiers de la recherche architecturale et urbaine, $\mathrm{N}^{\circ}$ 40: Imaginaire Technique, pp. 29-38.

Carpo, M. (2005). The demise of the identical. Architectural standardization in the age of digital reproducibility. Presented at the First International Conference on the Histories of Media, Art, Science and Technology, Banff: Banff Media Institute. Retrieved from http://www.banffcentre.ca/bnmi/ programs/archives/2005/refresh/docs/conferences/Mario_ Carpo.pdf

Carpo, M. (2015). Big Data are for adding, not for subtracting (pp. 23-27). Presented at the Colloquium "Mutations du projet. Milieux et cultures numériques," Paris.

Frampton. (2001). Studies in Tectonic Culture: The Poetics of Construction in Nineteenth and Twentieth Century Architecture by Frampton, Kenneth. The MIT Press, 2001.

Gámez, O., Bignon, J. C., \& Duchanois, G. (2015). Assisted Construction of Non-standard Wooden Walls and Envelope Structures by Parametric Modeling. In 16th International Conference, CAAD Futures 2015, São Paulo, Brazil, July 8-10, 2015. Selected Papers (Vol. 527, pp. 291-308). Sao Paulo, Brazil: Springer Berlin Heidelberg.

Gramazio, F., Kohler, M., \& Oesterle, S. (2010). Encoding material. AD, 80(4), 108-115.

Kolarevic, B. (2005). Architecture in the Digital Age: Design and Manufacturing (New Ed edition). New York: Taylor \& Francis.

Kondziela, A. (2011). The Endless Wall, ETH Zurich. Retrieved September 7, 2015, from http://gramaziokohler.arch.ethz.ch/ web/e/forschung/216.html

Leach, N. (2009). Digital Morphogenesis. Architectural Design, 79(1), 32-37. http://doi.org/10.1002/ad.806

Li, C. Q. (2013, June). Kreod. Pavilion Architecture. Concept, (170), 16-25.

Lynn, G. (1999). Animate Form. New York: Princeton Architectural Press.

Meyer, J., Bignon, J.-C., Duchanois, G., \& Bouali, A. (2015). Computer Design and Digital Manufacturing of Folded Architectural Structures Composed of Wood Panels. In Proceedings of the 20th International Conference of the Association for Computer-Aided Architectural Design Research in Asia (CAADRIA 2015) (pp. 653-662). Daegu.

Oxman, R. (2006). Theory and design in the first digital age. Design Studies, 27(3), 229-265. http://doi.org/10.1016/j. destud.2005.11.002

Roudavski, S. (2009). Towards Morphogenesis in Architecture. International Journal of Architectural Computing, 7(3), 345374. http://doi.org/10.1260/147807709789621266

Scheurer, F. (2010, July 1). Materializing complexity. Architectural Design, 80(4), 86-93.

Sekularac, N., Ivanovic-Sekularac, J., \& Cikic-Tovarovic, J. (2012). Folded structures in modern architecture. Facta Universitatis - Series: Architecture and Civil Engineering, 10(1), 1-16. http://doi.org/10.2298/FUACE1201001S

Sharif, S. and T. R. G. (2015). Design Cognition Shift from Craftsman to Digital Maker. In Proceedings of the 20th International Conference of the Association for ComputerAided Architectural Design Research in Asia (CAADRIA 2015) (pp. 683-692). Daegu. 
Stavric, M., Wiltsche, A., \& Bogensperger, T. (2015). Generative Design for Folded Timber Structures. In Proceedings of the 20th International Conference of the Association for Computer-Aided Architectural Design Research in Asia (CAADRIA 2015) (pp. 673-682). Daegu.
Weaver, W. (1948). Science and Complexity. American Scientist, 36(536), 535-544.

Zellner, P. (1999). Hybrid Space: Generative Form and Digital Architecture. New York: Rizzoli. 